
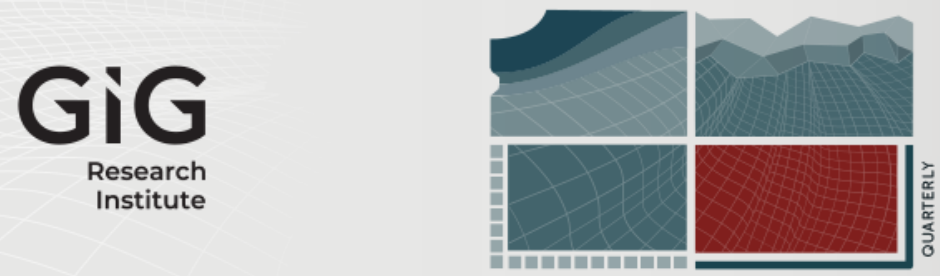

JOURNAL

OF

SUSTAINABLE

MINING

\title{
Blast-Induced Noise Level Prediction Model Based on Brain Inspired Emotional Neural Network
}

Author(s) ORCID Identifier:

Victor Amoako Temeng (iD) 0000-0002-9536-0871

Yao Yevenyo Ziggah (iD 0000-0002-9940-1845

Clement Kweku Arthur (iD) 0000-0002-4954-1532

Follow this and additional works at: https://jsm.gig.eu/journal-of-sustainable-mining

Part of the Mining Engineering Commons

\section{Recommended Citation}

Temeng, Victor Amoako; Ziggah, Yao Yevenyo; and Arthur, Clement Kweku (2021) "Blast-Induced Noise Level Prediction Model Based on Brain Inspired Emotional Neural Network," Journal of Sustainable Mining: Vol. 20 : Iss. 1 , Article 3.

Available at: https://doi.org/10.46873/2300-3960.1043

This Research Article is brought to you for free and open access by Journal of Sustainable Mining. It has been accepted for inclusion in Journal of Sustainable Mining by an authorized editor of Journal of Sustainable Mining. 


\title{
Blast-Induced Noise Level Prediction Model Based on Brain Inspired Emotional Neural Network
}

\begin{abstract}
Although a major portion of the emitted energy from mine blast is sub-audible (lower frequency), there exist a component that is audible (high frequencies from $20 \mathrm{~Hz}$ to $20 \mathrm{KHz}$ ) and as such within the range of human hearing as noise. Unlike blast air overpressure (low frequency occurrence), noise prediction from mine blasting has received little scholarly attention in mining sciences. Noise from mine blast is considered a major detrimental blasting effect and can be a menace to nearby residents and workers in the mine. In this paper, a blast-induced noise level prediction model based on Brain Inspired Emotional Neural Network (BENN) is presented. The objective of this paper was to investigate the implementation possibility of the proposed BENN approach along with six other artificial intelligent methods, such as Backpropagation Neural Network (BPNN), Radial Basis Function Neural Network (RBFNN), Generalised Regression Neural Network (GRNN), Group Method of Data Handling (GMDH), Least Squares Support Vector Machine (LSSVM) and Support Vector Machine (SVM). The study also implemented the standard Multiple Linear Regression (MLR) for comparison purposes. The statistical analysis carried out revealed that the BENN performed better than the other investigated methods. Thus, the BENN achieved very promising testing results of $1.619 \mathrm{~dB}, 3.076 \%, 0.0925 \%, 0.911$ and $82.956 \%$ for root mean squared error (RMSE), mean absolute percentage error (MAPE), normalised root mean squared error (NRMSE), correlation coefficient $(R)$ and variance accounted for (VAF). The implemented BENN can be useful in managing noise from mine blasting using site specific data.
\end{abstract}

\section{Keywords}

Artificial intelligence, Blast-induced noise level, Emotional neural network, Limbic system theory

\section{Creative Commons License}

\section{(c) (i)}

This work is licensed under a Creative Commons Attribution 4.0 License.

\section{Cover Page Footnote}

The authors thank the Ghana National Petroleum Corporation (GNPC) for providing funding to support this work through the GNPC Professorial Chair in Mining Engineering at the University of Mines and Technology (UMaT), Ghana. 


\title{
Blast-induced noise level prediction model based on Brain Inspired Emotional Neural Network
}

\author{
Victor Amoako Temeng ${ }^{a}$, , Yao Yevenyo Ziggah ${ }^{b}$, Clement Kweku Arthur ${ }^{a}$ \\ ${ }^{a}$ Faculty of Mineral Resources Technology, Department of Mining Engineering, University of Mines and Technology, Tarkwa, Ghana \\ ${ }^{b}$ Faculty of Mineral Resources Technology, Department of Geomatic Engineering, University of Mines and Technology, Tarkwa, Ghana
}

\begin{abstract}
Although a major portion of the emitted energy from mine blast is sub-audible (lower frequency), there exist a component that is audible (high frequencies from $20 \mathrm{~Hz}$ to $20 \mathrm{KHz}$ ) and as such within the range of human hearing as noise. Unlike blast air overpressure (low frequency occurrence), noise prediction from mine blasting has received little scholarly attention in mining sciences. Noise from mine blast is considered a major detrimental blasting effect and can be a menace to nearby residents and workers in the mine. In this paper, a blast-induced noise level prediction model based on Brain Inspired Emotional Neural Network (BENN) is presented. The objective of this paper was to investigate the implementation possibility of the proposed BENN approach along with six other artificial intelligent methods, such as Backpropagation Neural Network (BPNN), Radial Basis Function Neural Network (RBFNN), Generalised Regression Neural Network (GRNN), Group Method of Data Handling (GMDH), Least Squares Support Vector Machine (LSSVM) and Support Vector Machine (SVM). The study also implemented the standard Multiple Linear Regression (MLR) for comparison purposes. The statistical analysis carried out revealed that the BENN performed better than the other investigated methods. Thus, the BENN achieved very promising testing results of $1.619 \mathrm{~dB}, 3.076 \%, 0.0925 \%, 0.911$ and $82.956 \%$ for root mean squared error (RMSE), mean absolute percentage error (MAPE), normalised root mean squared error (NRMSE), correlation coefficient $(R)$ and variance accounted for (VAF). The implemented BENN can be useful in managing noise from mine blasting using site specific data.
\end{abstract}

Keywords: artificial intelligence, blast-induced noise level, emotional neural network, limbic system theory

\section{Introduction}

$\mathrm{L}$ oading, hauling, crushing, grinding and milling are the major constituents of downstream activities in mine operations which are geared towards achieving high mineral recovery rate. For optimum downstream operations, controlled blasting is the predominant measure usually employed to fragment consolidated mineral deposits in a surface or underground mine. Implementing controlled blasting increases mine efficiency and productivity which can lead to substantial savings in mining cost and control adverse blast-induced environmental effects such as noise, air blast, ground vibration, fly rock and over-break. Adopting controlled blasting measure also contributes to easing issues relating to public relation and improves significantly the safety standard.

Modelling and predicting adverse blast-induced environmental effects is a hot topic in mining sciences. Because of that, several mathematical methods have been proposed in literature. The most notable blast-induced environmental effects that are well investigated include ground vibration [1,2], air blast [3], flyrock $[4,5]$ and over-break [6,7]. From literature, it was evident that prediction of blastinduced noise has been under explored and thus given little scholarly attention within the mining science community. That is, the existing literature have only considered noise generated from the operation of different set of mine machineries used in surface and underground mines [8-16].

Received 10 December 2020; revised 10 February 2021; accepted 18 February 2021.

Available online 26 March 2021

* Corresponding author.

E-mail address: vatemeng@umat.edu.gh (V.A. Temeng). 
Therefore, prediction studies into blast-induced noise is an area which needs to be explored to safeguard the working environment and the mining community at large.

Generally, noise is classified as environmental hazard which is found to be among the impacts of blasting on the environment. In order to achieve minimum negative impact of noise in a mine and its surrounding communities, it is essential to find ways of optimising mine blasting. It is a matter of the utmost importance to understand the causal agents and their influence on a blast design. This is because a well-designed blast will produce optimum blast-induced noise level that falls within the allowable threshold value. In the light of this, highly potent mathematical predictive tools are needed to provide prior blasting outcome information to the blast engineer. Moreover, in view of the complexity and nonlinearity of the blast designed parameters, a highly accurate nonlinear predictive model is indeed necessary for step ahead noise estimation prior to blasting.

It is interesting to know that traditional Artificial Intelligence (AI) techniques such as Adaptive Neuro Fuzzy Inference System (ANFIS), Backpropagation Neural Network (BPNN) and Radial Basis Function Neural Network (RBFNN) have generally been applied by scholars to predict different noise sources [8-27] other than blast-induced noise. The use of these methods have been typically influenced by its ability to adaptively handle nonlinear data sets in an adequate manner. On the contrary, it has been found that most of the traditional AI methods often exhibit some practical drawbacks such as manually fine-tuning adjustable parameters, less convergence speed due to the use of gradient training algorithms, results not achieving global optimum, suffering from curse of dimensionality and high computational cost [28]. In contrast to the traditional AI methods, the limbic system theory of Brain Inspired Emotional Neural Network (BENN) has been found to offer certain practical advantages and is considered as a reliable alternative. Practically, the BENN approach eliminates manual tasking in the model development, offers strong calibration and generalisation performance, provides quick reaction and instinctively process external information with reduction in computational complexity [28]. In view of BENN strengths, this study explored its capability as a new forecasting technique in blast-induced noise level prediction.

To show the excellent generalisation strength of BENN, the standard multiple linear regression
(MLR) and six other AI methods were also applied for comparison. The AI methods applied to be compared with BENN included BPNN, RBFNN, Generalised Regression Neural Network (GRNN), Group Method of Data Handling (GMDH), Least Squares Support Vector Machine (LSSVM) and Support Vector Machine (SVM). These methods have been selected for comparison because they are the most widely used by scholars in predicting other investigated adverse effects of blasting (e.g. ground vibration, flyrock, air overpressure, etc.). Hence, they are deemed appropriate to be used in this study for comparison with the BENN approach. The present study is a contribution to body of knowledge and will fill the literature gap in the use of $\mathrm{AI}$ for modelling and prediction of blast-induced noise. The study will further advance the application frontiers of the limbic based system of BENN and will confirm its universal function approximation capabilities. The statement is buttressed by the fact that despite the extensive application of BENN in different disciplines [28-37], the method has not fully explored in the direction of blast-induced noise level prediction studies.

\section{Proposed method}

In this study, the BPNN, RBFNN, GRNN, GMDH, LSSVM, SVM and MLR methods were applied for comparison purpose because they are widely regarded as benchmark methods. There has been extensive literature in mining science to ascertain their capability to predict other blast-induced environmental effects such as ground vibration, air blast, flyrock and over-break. Detailed information on them can be found in Refs. [1-7]. This section only presents the theoretical and mathematical background of BENN.

The BENN considers the anatomical and physiological conditions of the mammalian brain by artificially mimicking the nervous system [28]. This technique has been found to evolve from the limbic system of the mammalian brain that handles emotions and memory. In the limbic system, several brain structures such as amygdala, thalamus, orbitofrontal cortex, sensory cortex, hippocampus and hypothalamus are involved. As can be seen in Fig. 1, for BENN the thalamus serves as a channel to receive input neurons from the outside world which are then transferred directly to the sensory cortex for further processing. In the amygdala, information is received in two different ways. The first is receiving imprecise expanded input neurons 


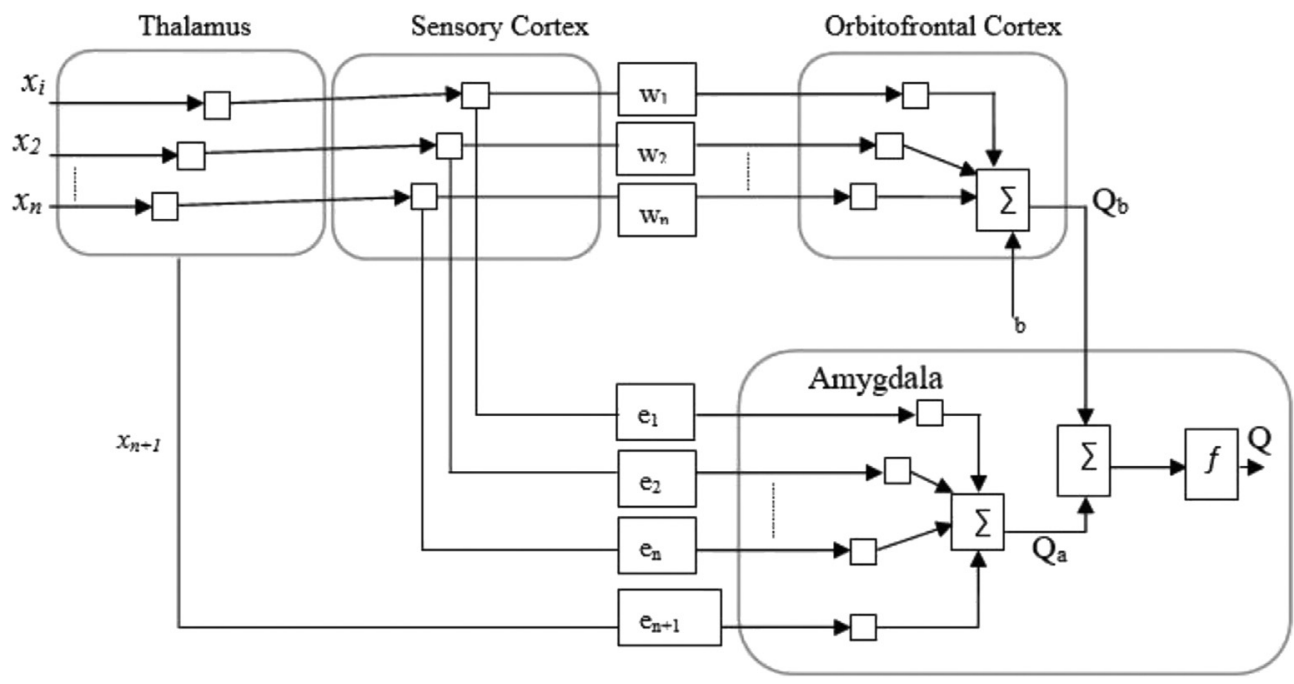

Fig. 1. General BENN structure.

directly from the thalamus through the least path of sensory information transmission. The second is receiving precise information from the sensory cortex through the longest path of sensory information transfer. The orbitofrontal cortex handles the convergence of the processed information from the sensory cortex and inhibit the inappropriate amygdala responses to achieve the preferred outcome. It must be noted that accurate response can be found by the BENN system at the amygdala-orbitofrontal cortex interaction.

Practically, the motive of applying BENN in this study is to create a model that can adequately predict blast-induced noise level given a set of input data $X=\left\{x_{1}, x_{2}, \ldots, x_{n+1}\right\}$ and target data $Y=\left\{y_{1}, y_{2}\right.$, $\left.\ldots y_{n+1}\right\}, \quad n=1,2,3, \ldots N$. Relating the $X$ and $Y$ information to the BENN structure (Fig. 1), the thalamus directly receives the $X$ data which is then sent to the sensory cortex. The sensory cortex data is then transmitted to the orbitofrontal cortex. The amygdala then receives the imprecise response from the thalamus designated as $x_{n+1}$ (Eq. (1)) and precise response from the sensory cortex based on the input data $x_{1}, x_{2}, \ldots, x_{n}$.

$x_{n+1}=\operatorname{mean}_{j=1, \ldots, n}\left(x_{j}\right)$

In order to simulate the imprecision exhibited in the thalamus response, the mean operator (Eq. (2)) is used.

$Q=Q_{a}-Q_{b}$

where $Q$ is the final response, $Q_{a}$ (Eq. (3)) and $Q_{b}$ (Eq. (4)) represent the various responses from amygdala and orbitofrontal cortex. Equation (2) signifies that for the BENN system, $Q$ is heavily reliant on the interaction between amygdala and orbitofrontal cortex. However, the orbitofrontal cortex in the computational process limits the influence of amygdala imprecise response in the final outputs [38,39].

$Q_{a}=\sum_{j=1}^{n+1}\left(e_{j} \times x_{j}\right)$

$Q_{b}=\sum_{j=1}^{n}\left(w_{j} \times x_{j}\right)+b$

where $e_{j}$ and $w_{j}$ are the respective weights for the amygdala and orbitofrontal cortex. The $x_{j}$ is the input data and $b$ is the bias term in the orbitofrontal cortex. Weight adaptation was done in the training process using genetic algorithm. In this study, the BENN blast-induced noise level prediction model was created by modifying the MATLAB program proposed by Ref. [40].

\section{Study area and data description}

\subsection{Study area}

The case study is a mining company (hereafter Mine X) located in the Western Region of Ghana. Mine $X$ is located approximately $4 \mathrm{~km}$ west of the Tarkwa Nsuaem Municipality and $60 \mathrm{~km}$ to the South of the Atlantic coast with a topography dominated by pronounced ridges and valleys. These ridges are mainly composed of the Banket Series 


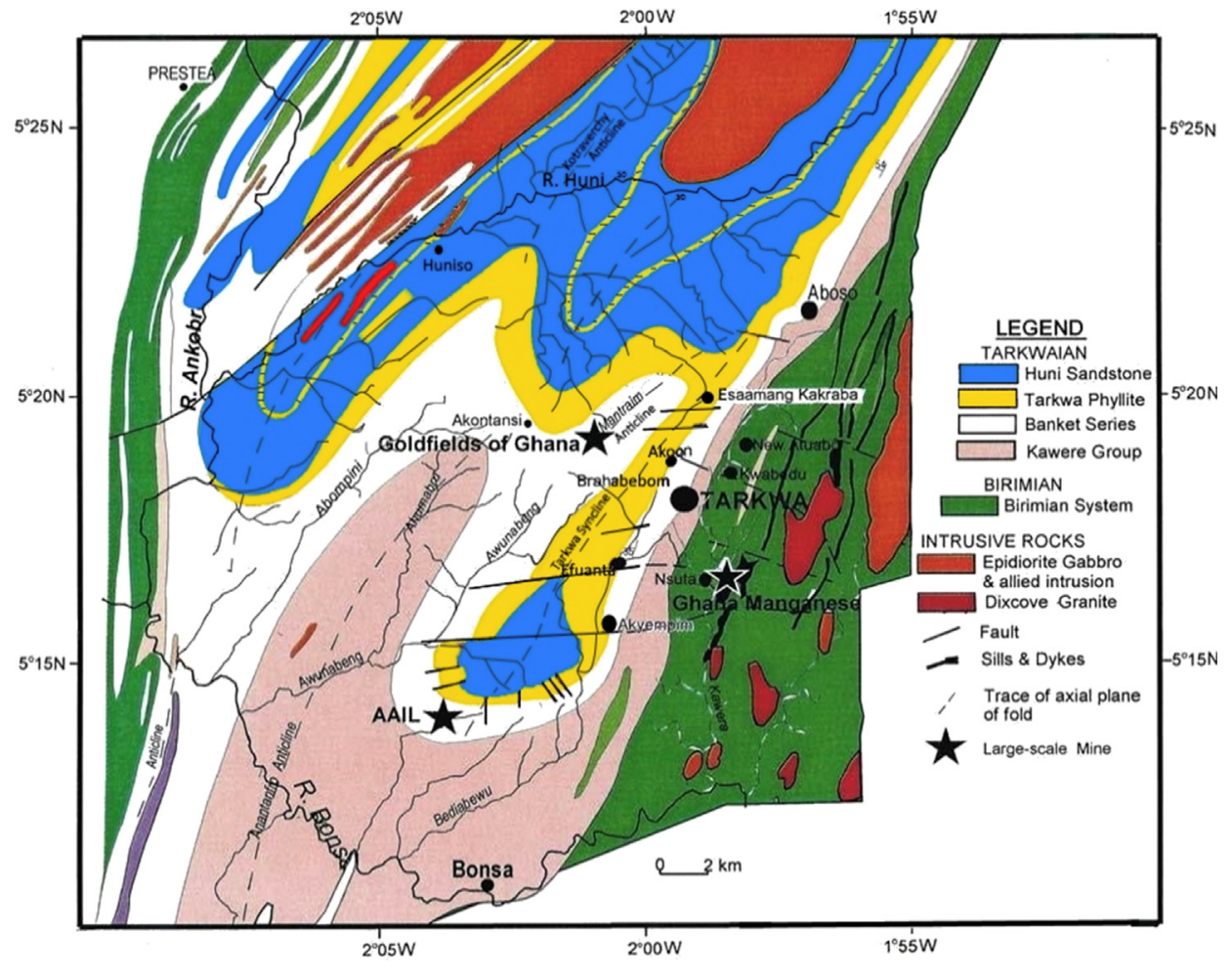

Fig. 2. Geological setting of the study area.

and Tarkwa Phyllites with the low-lying areas dominated by sandstones/quartzites [41]. The Tarkwa basin is filled with a fine upward sequence of clastic sedimentary rocks known as the Tarkwaian Group which are of Proterozoic age. Fig. 2 shows the geological setting of the study area.

Mine X employs the surface mining method and operates six open pits which have been divided into two sections with each section constituting three open pits. Four standard units of downstream operations namely drilling, blasting, loading and hauling are employed to fragment rocks and haul the fragmented material to the run-off-mine pad. The Mine uses Pantera (Sandvik DP 1500i) and Epiroc drill rigs for drilling blast holes. The drilling parameters include $9 \mathrm{~m}$ bench height with $1.2 \mathrm{~m}$ sub-drill with hole diameter of $127 \mathrm{~mm}$ for blast production holes and $115 \mathrm{~mm}$ for drilling pre-split or buffer holes. The staggered blast patterns are employed by the Mine using different burden and spacing depending on the rock conditions for both ore and waste. The burden and spacing mostly employed include $3.5 \mathrm{~m} \times 3.5 \mathrm{~m}, 3.5 \mathrm{~m} \times 4.0 \mathrm{~m}$ and $4.0 \mathrm{~m} \times 4.0 \mathrm{~m}$. Blasting of in situ rock involves the use of blend type of water resistance bulk explosive (S130) which is made up of $70 \%$ emulsion and $30 \%$ ammonium nitrate. The nonel and electronic initiators are respectively used for blast hole initiation of the mine. The mining fleet is a combination of excavators (Liebherr 9250, Liebherr 9350 and Liebherr 996B), 100-tonne (CAT 777D) and 144-tonne (CAT 785D) capacity haul trucks.

\subsection{Data description}

In order to develop the blast-induced noise level prediction model, 324 blast events data were acquired from Mine X. The data collected comprised of blast design and explosive parameters obtained from the daily blast design plan. These included number of blast holes, maximum instantaneous charge $(\mathrm{kg})$, blast hole depth $(\mathrm{m})$, stemming length $(\mathrm{m})$, powder factor $\left(\mathrm{kg} / \mathrm{m}^{3}\right)$, total charge $(\mathrm{kg})$ and, distance from monitoring and blasting site $(\mathrm{m})$. It is important to know that the distance between monitoring station and blast point is computed using the two-dimensional Euclidean distance (ED) formula (Eq. (5)). 
$\mathrm{ED}=\sqrt{\left(E_{M S}-E_{B P}\right)^{2}+\left(N_{M S}-N_{B P}\right)^{2}}$

where $E_{M S}$ and $N_{M S}$ represent Easting and Northing coordinates for the monitoring stations while $E_{B P}$ and $N_{B P}$ is the coordinate of the blast point.

The Instantel Micromate Seismograph instrument comprising of a single geophone and a microphone is used to measure the noise from mine blasting. In the field of observation, the geophone is firmly fixed on the ground at a nearby house closest to the Mine pit with the geophone arrow directed towards the blast location. Thus, the Instantel Micromate Seismograph was set at the same distance (location) with different direction depending on the position of the blast. Hence, the monitoring could be behind, at the side or in front of the blast face depending on the blast location. It is worth stating that the noise monitoring was carried out at a different elevation relative to the mining face as the monitoring was done at the nearest building in the neighbouring community to the mining pit which has been mined downwards. Prior to blasting, mining equipment are parked at a safe distance away from the blasting area with all activities within and outside the pit halted to ensure the recorded noise level are only due to blasting. In order to avoid external influence and ensure accurate blast-induced noise level recordings, the seismic instrument is calibrated before readings are made. In the calibration process, the seismic instrument is first set to a continuous reading mode after which the ambient (surrounding) noise levels are recorded. These recorded ambient noise levels then serve as the below detection levels to overcome any surrounding noise levels throughout the monitoring and recording the blast. Descriptive statistics of the data set used is presented in Table 1.

\section{Model development process}

The BENN blast-induced noise level prediction model was developed using a total of 324 data sets.
The data was then divided into training and testing sets, respectively. The training set which is made up of 227 data points constituting $70 \%$ of the entire data were used to build and fit the model. The trained model was independently validated using the remaining 30\% (97 data points). The percentage divisions of the data was based on the commonly used hold-out cross validation approach in literature [42-45]. The issues of over- and underfitting where the trained model over- and under-estimate the test data were taken into account during the model training phase using the RMSE criterion. Thus, the optimum model was achieved by selecting the trained model that provided the lowest RMSE with respect to the test data and thus has a minimal difference between the training and testing RMSE. In the model building, the blast design and explosive parameters used as input variables include the number of blast holes, maximum instantaneous charge $(\mathrm{kg})$, blast hole depth $(\mathrm{m})$, stemming length $(\mathrm{m})$, total charge $(\mathrm{kg})$, distance from monitoring and blasting site $(\mathrm{m})$ and powder factor $(\mathrm{kg} / \mathrm{m} 3)$.

Practically, it is a well-known fact in blast management that, the effectiveness of a blast is affected by the entire facets of blast design. Therefore, a number of interconnected blast design parameters which are deemed relevant must be considered in the model development process. These assertions have been echoed in literature that the selected input parameters used in this study have been found to have massive influence in predicting mine blasting outcomes such as air overpressure, ground vibration, fly rock, over break, etc. Additionally, the selected input parameters used in this study are in consonance with the practice of most scholars when predicting the aforementioned blasting outcomes [46-54]. Hence, it was deemed fit to use the selected input parameters for predicting the blast-induced noise level $(\mathrm{dB})$ considered in this study.

In order to improve the computational convergence of the various methods applied, data

Table 1. Descriptive statistics of the variables for the entire data (total observation=324).

\begin{tabular}{lllll}
\hline Variables & Statistic & & \\
\cline { 2 - 5 } & Mean & Standard Deviation & Minimum & Maximum \\
\hline Number of blast holes & 106.753 & 65.309 & 13.00 & 423 \\
Maximum instantaneous charge $(\mathrm{kg})$ & 72.270 & 31.400 & 10.76 & 175 \\
Blast hole depth (m) & 8.256 & 1.949 & 3.40 & 10.20 \\
Stemming length (m) & 3.197 & 0.382 & 1.80 & 3.50 \\
Total charge (kg) & 8091.99 & 6782.20 & 495 & 49.100 \\
Distance from monitoring to blasting site (m) & 1312.40 & 516.37 & 518 & 3862 \\
Powder factor $\left(\mathrm{kg} / \mathrm{m}^{3}\right)$ & 0.672 & 0.177 & 0.24 & 2.07 \\
Noise $(\mathrm{dB})$ & 42.879 & 4.157 & 33.10 & 53.40 \\
\hline
\end{tabular}


normalisation was first performed on the input data into the interval $[-1,1]$ using Eq. (6) [55].

$b_{i}=b_{\min }+\frac{\left(b_{\max }-b_{\min }\right) \times\left(c_{i}-c_{\min }\right)}{\left(c_{\max }-c_{\min }\right)}$

where $b_{i}$ is the normalised data, $c_{i}$ is the input data, $c_{\max }$ and $c_{\min }$ are the input variable's maximum and minimum values with $c_{\max }$ and $c_{\min }$ taking on values of 1 and -1 .

In the model validation phase, the following statistical performance metrics were used to assess the predictive strength of the models developed. These were the root mean square error (RMSE), normalised root mean square error (NRMSE), mean absolute percentage error (MAPE), variance accounted for (VAF) and correlation coefficient $(R)$. These are represented mathematically in Eqs. (7)-(11).

$R M S E=\sqrt{\frac{1}{N} \sum_{i=1}^{N}\left(T_{i}-P_{i}\right)^{2}}$

$M A P E=\frac{100 \%}{N} \sum_{i=1}^{N} \frac{\left|T_{i}-P_{i}\right|}{T_{i}}$

$N R M S E=\frac{R M S E}{T_{\max }-T_{\min }}$

$R=\left(\frac{\sum_{i=1}^{N}\left(T_{i}-\bar{T}\right)\left(P_{i}-\bar{P}\right)}{\sqrt{\sum_{i=1}^{N}\left(T_{i}-\bar{T}\right)^{2}} \times \sqrt{\sum_{i=1}^{N}\left(P_{i}-\bar{P}\right)^{2}}}\right)$

$V A F=\left[1-\frac{\operatorname{var}\left(T_{i}-P_{i}\right)}{\operatorname{var}\left(T_{i}\right)}\right] \times 100$

where $T_{i}$ and $P_{i}$ represent the measured and predicted blast-induced noise level. $T_{\max }$ and $T_{\min }$ are the maximum and minimum values of the measured blast-induced noise level. The $\bar{T}$ and $\bar{P}$ are the average values for the measured and predicted blast-induced noise level. $N$ depicts the total blast-

Table 2. BENN model performance results.

\begin{tabular}{llll}
\hline Statistical Indicators & \multicolumn{2}{l}{ BENN Model } & Unit \\
\cline { 2 - 3 } & Training & Testing & \\
\hline RMSE & 1.679 & 1.619 & $\mathrm{~dB}$ \\
MAPE & 2.904 & 3.076 & $\%$ \\
NRMSE & 0.083 & 0.092 & $\%$ \\
R & 0.907 & 0.911 & - \\
VAF & 82.187 & 82.956 & $\%$ \\
\hline
\end{tabular}

induced noise level data and $i$ takes values from 1 to $N$.

\section{Results and discussion}

\subsection{BENN blast-induced noise level prediction} model

The BENN approach uses the simulated human brain emotional process to train the network. It is important to note that BENN proposed in Lotfi [28] uses the genetic algorithm to fine-tune the numerical weights of the network. In this study, the widely used sequential trial and error approach was adopted to determine the best population size and number of generations that can produce the best BENN blast-induced noise level predictions. After several trials in this study, a population size of 100 and 1000 number of generations produced the optimum BENN results. The optimum model was obtained by selecting the model that attains the best values with respect to the performance criteria (Eqs. (7) to (11)) utilised.

Table 2 presents the training and testing results for the various performance criteria used to assess the validity of the BENN model. In Table 2, it can be seen that there is no evidence of over-fitting condition because of the peculiar characteristic feature of the training and testing results. That is, the obtained training and testing results based on the statistical indicators have closely related values with only some slight difference between them. This means that the BENN has greater learning capabilities with regards to the training data and could generalise adequately on the testing data. From the error indicators (RMSE, MAPE and NRMSE) (Table 2), it can generally be interpreted that the BENN blast-induced noise level predictions are close to the measured data points. In Table 2, the $\mathrm{R}$ and VAF that generally show the relative measure of fit show that the BENN model when applied produced highly accurate blast-induced noise level predictions.

\subsection{Comparison of BENN and other applied methods}

The BENN blast-induced prediction model result was compared with six AI methods (BPNN, RBFNN, GRNN, GMDH, LSSVM and SVM) and classical MLR approach. These comparative methods were chosen because they have been found in literature to be the most widely used in both noise related works and predicting blasting outcomes (e.g. ground vibration, air blast, fly rock, etc.). Hence, 
they are categorised as benchmark techniques and suitable for comparison purpose. It is important to indicate that the same training and testing data sets used for the BENN technique were used to develop the prediction models for the mentioned comparative methods. The same optimum model selection criteria used for the BENN were employed for the other investigated methods.

In the BPNN, the best performing model architecture was [7-4-1] that is, seven inputs, four hidden neurons and one output. In the training phase, the Levenberg Marquardt algorithm [56] was used for the weight adaptation. In the hidden and output layers, the hyperbolic tangent and linear activation functions [57] were respectively utilised. The momentum coefficient and learning rate values used were 0.7 and 0.03 respectively. For the RBFNN, the optimum model structure was seven inputs, twenty two hidden neurons and one output, that is [7-22-1] with a smoothing parameter of 16.1. The optimum GRNN model performance had a smoothing parameter of 0.11 . To train the LSSVM model, the linear kernel function with regularisation parameter value of 0.49213 produced the best prediction results. A polynomial kernel function of order 1 and penalty factor value of 50 with error parameter factor set at $1.00 \times 10^{-8}$ produced the optimum SVM model predictions. The best performing GMDH model had four layers, four used variables in the input layer and one neuron in both successive hidden and output layers. The GMDH has a feature extraction capability and that was demonstrated when the final model was established. This can be seen in Table 3 where only four parameters (number of blast holes, maximum instantaneous charge, stemming length and distance from monitoring to blasting site) out of the seven were selected as the most relevant parameters in the GMDH model building.

$\mathrm{NB}: x_{1}$ is the number of blast holes, $x_{2}$ is the maximum instantaneous charge, $x_{4}$ is the stemming length and $x_{6}$ is the distance from monitoring to blasting site.

Table 4. Model adequacy assessment test results.

\begin{tabular}{llllll}
\hline Model & RMSE (dB) & MAPE (\%) & NRMSE (\%) & R & VAF (\%) \\
\hline BENN & 1.619 & 3.076 & 0.092 & 0.911 & 82.956 \\
BPNN & 1.621 & 3.214 & 0.093 & 0.914 & 82.839 \\
RBFNN & 1.629 & 3.202 & 0.093 & 0.919 & 82.944 \\
GRNN & 1.944 & 3.689 & 0.111 & 0.874 & 75.578 \\
GMDH & 1.809 & 3.597 & 0.103 & 0.905 & 79.481 \\
LSSVM & 1.642 & 3.186 & 0.094 & 0.910 & 82.673 \\
SVM & 1.906 & 3.825 & 0.109 & 0.909 & 77.729 \\
MLR & 2.827 & 3.126 & 0.162 & 0.821 & 82.879 \\
\hline
\end{tabular}




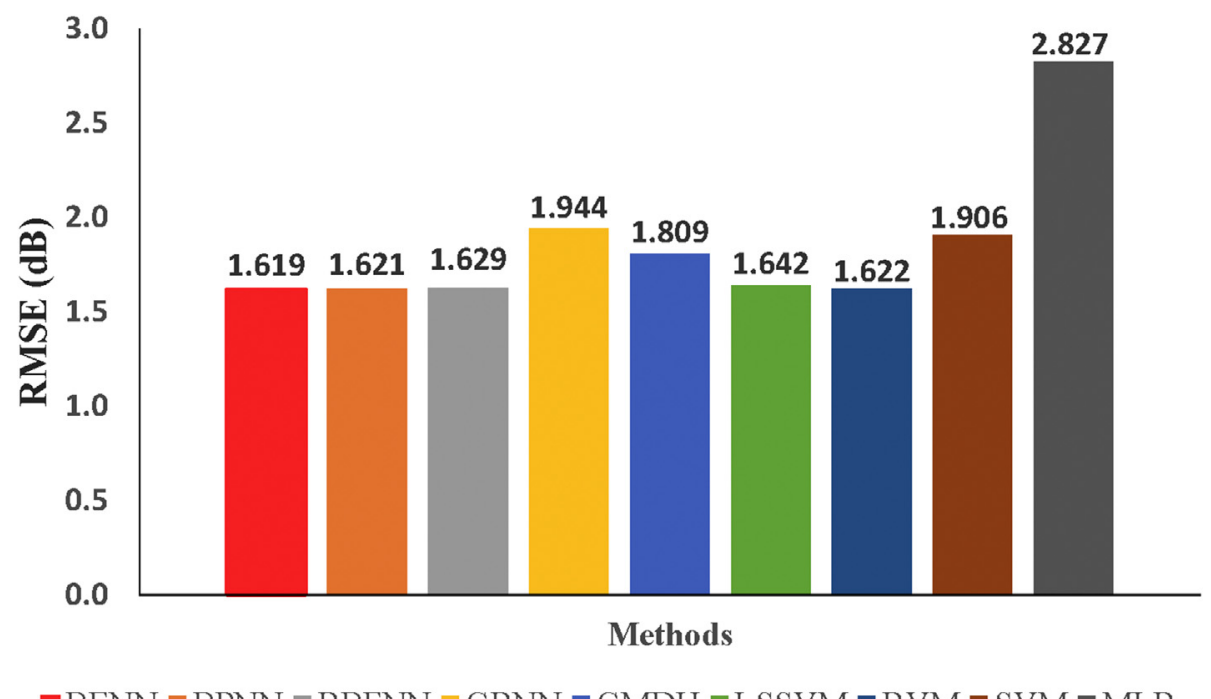

Fig. 3. RMSE test results for the various models.

The MLR predicted model developed is of the form shown in Eq. (12) where $x_{1}, x_{2}, x_{3}, x_{4}, x_{5}, x_{6}$ and $x_{7}$ are number of blast holes, maximum instantaneous charge, blast hole depth, stemming length, total charge, distance from monitoring to blasting site, and powder factor respectively.
The practical usefulness of the proposed BENN and the other investigated approaches were assessed based on the testing data. This was essential because the testing data was not used at the initial formulation of the models and thus can provide independent validity assessment of the

$$
\begin{aligned}
\text { MLR Model }= & 47.29732+1.6277 \times 10^{-02}\left(x_{1}\right)+9.8254 \times 10^{-02}\left(x_{2}\right)-0.80765\left(x_{3}\right) \\
& 1.406725\left(x_{4}\right)+4.82 \times 10^{-05}\left(x_{5}\right)-0.00776\left(x_{6}\right)-1.83105\left(x_{7}\right)
\end{aligned}
$$

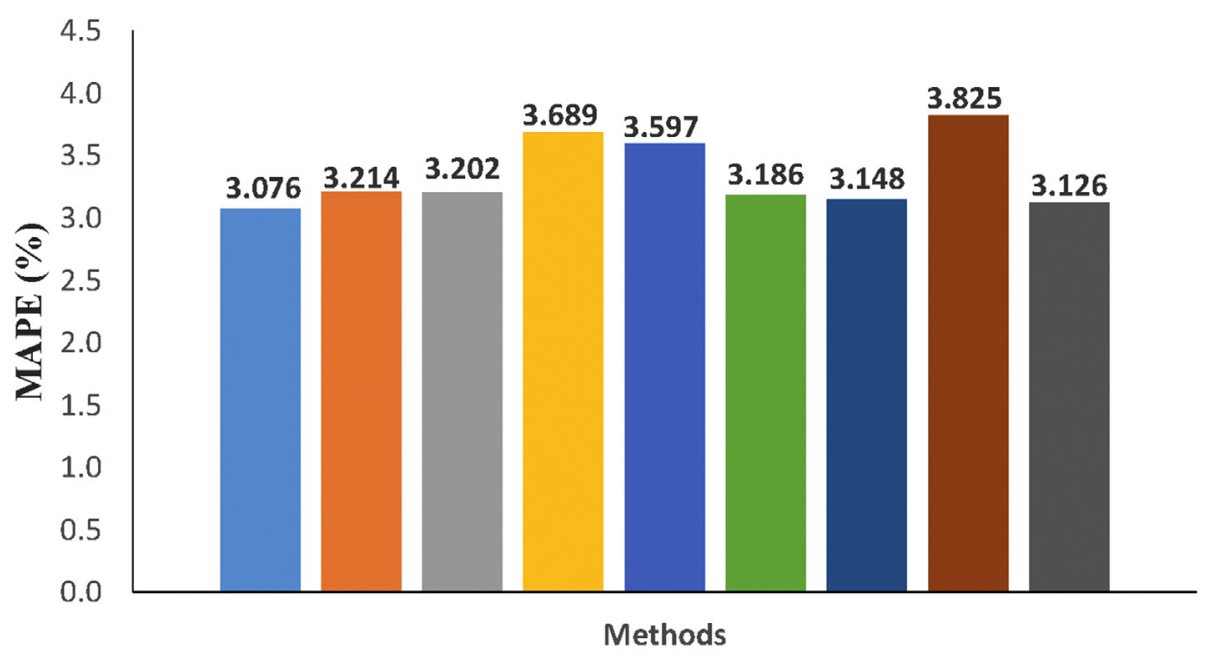

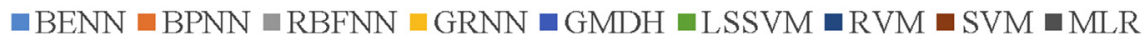

Fig. 4. MAPE test results for the various models. 


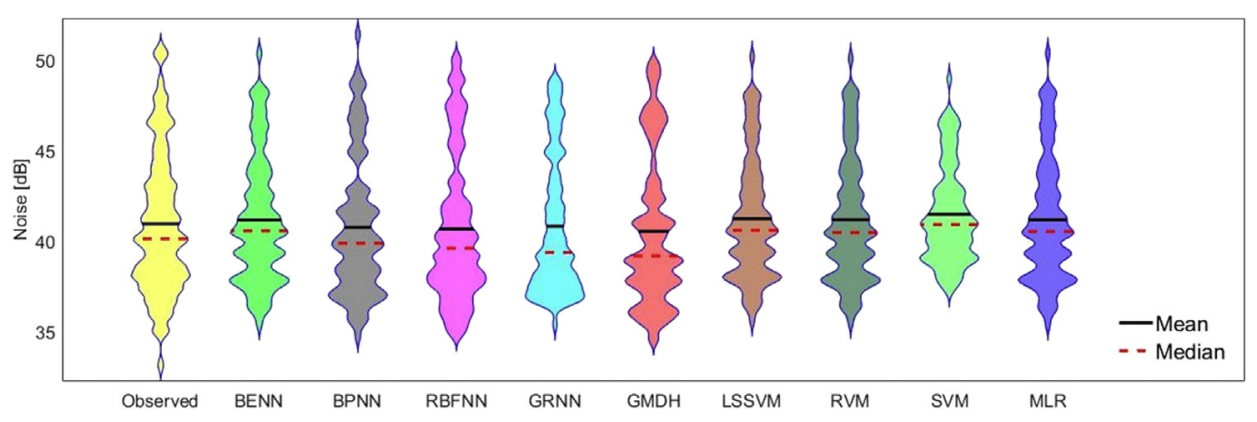

Fig. 5. Violin Plots for the Measured and Predicted Blast-induced Noise Level for each Model.

generalisation ability of the models developed. Table 4 shows the various models evaluation test results based on the statistical performance metrics applied.

The RMSE signifies a measure of a model predictive accuracy. Using the RMSE (Table 4), the comparative results obtained from the various models showed that the proposed BENN approach provides the best absolute fitted blast-induced noise level values to the measured test data. The interpretation here is that the BENN model outcomes were in better agreement to the measured blastinduced noise level than the other methods. With regards to the MAPE value, it can be explained that when the BENN model is applied a percentage error margin within $3.076 \%$ can be achieved which signify a prediction percentage accuracy of $96.924 \%$. On the contrary, BPNN, RBFNN, GRNN, GMDH, LSSVM, SVM and MLR achieved 96.786\%, 96.798\%, 96.311\%, $96.403 \%, 96.814 \%, 96.175 \%$ and $96.874 \%$ respectively. Pictorial representation of the RMSE and MAPE to confirm BENN predictive strength are shown in Figs. 3 and 4. The MAPE results are in consonance to the NRMSE value obtained by BENN which indicate less variations in the computed errors (difference between the measured and predicted test results). This buttresses the assertion that the closer the NRMSE (Table 4) value is to zero, the lower the residual variance which depict a minimal unexplained variability in the BENN predicted blast-induced noise level when compared with the measured test data.

Comparing the $R$ test results (Table 4), it was generally noted that the BENN, BPNN, RBFNN, GRNN, GMDH, LSSVM, SVM and MLR all had positive correlation coefficient values. It can be agreed that all the models exhibited a direct linear relationship between their predicted outputs and measured blast-induced noise level. In Table 4, although BENN, BPNN, RBFNN, LSSVM and MLR all produced VAF values above $80 \%$, BENN was slightly better than the others. This means that the
BENN could explain $82.956 \%$ of possible errors inhibited in its predicted results. It must be noted that the VAF value determines the prediction strength of the models. A VAF value bigger than $80 \%$ is categorised as excellent model, a VAF value between $20 \%$ and $80 \%$ means a good model, while a VAF value less than $20 \%$ means worse model. In line with that, the BENN was a much better model as compared to the other methods. It is worth clarifying that the different statistical results produced by all the models investigated is based on the degree of calibration and generalisation strength of a particular model on the training and testing data, respectively.

To further compare the accuracy of the developed models, violin plot (Fig. 5) of the predicted against the measured blast-induced noise level is presented. The violin plot provides the statistical distribution of the measured and predicted data. In Fig. 5, it can be seen that the predicted noise level distributions within each model show some form of variability. However, the variability noticed for the BENN predictions are fairly consistent and do not exhibit any skewness property in its distribution. The other models' variability can be seen to have some inconsistencies in their distributions. This shows that the BENN could correctly predict the blast-induced noise level at high precision and accuracy.

\section{Conclusions}

In this paper, the BENN has been proposed and applied to predict blast-induced noise level. The BENN was compared with six AI methods (BPNN, RBFNN, GRNN, GMDH, LSSVM and SVM) and MLR approach. Comparative analysis was carried out using statistical performance metrics of RMSE, MAPE, NRMSE, $R$ and VAF. From the experimental results, it was revealed that the proposed BENN approach has better calibration and prediction capabilities than that of the other methods. Besides, the BENN architectural design enables automatic 
computational process and is thus devoid of human interference with final results produced without parameter settings. Hence, it is mathematically sound and attractive to adopt and employ BENN in managing blast-induced noise level in the mines. Consequently, this study as a major contribution has provided scholarly attention to blast-induced noise level prediction in mining sciences with BENN introduced as a novel computational predictive tool. A limitation of this study is the lack of empirical equations and previous studies on the topic under study. Therefore, for future research, there is the need to develop empirical noise predictor equations that accept blasting and explosive design parameters as its input variables. This will in general expand the research frontiers of noise prediction.

\section{Conflicts of interest}

None declared.

\section{Ethical statement}

The authors state that the research was conducted according to ethical standards.

\section{Funding body}

This research was funded by Ghana National Petroleum Corporation (GNPC) Professorial Chair in Mining Engineering at the University of Mines and Technology (UMaT), Ghana.

\section{References}

[1] Jiang W, Arslan CA, Tehrani MS, Khorami M, Hasanipanah M. Simulating the peak particle velocity in rock blasting projects using a neuro-fuzzy inference system. Eng Comput 2019;35(4):1203-11.

[2] Mokfi T, Shahnazar A, Bakhshayeshi I, Derakhsh AM, Tabrizi O. Proposing of a new soft computing-based model to predict peak particle velocity induced by blasting. Eng Comput 2018;34(4):881-8.

[3] Hasanipanah M, Armaghani DJ, Khamesi H, Amnieh HB, Ghoraba S. Several non-linear models in estimating airoverpressure resulting from mine blasting. Eng Comput 2016;32(3):441-55.

[4] Guo H, Zhou J, Koopialipoor M, Armaghani DJ, Tahir MM. Deep neural network and whale optimization algorithm to assess flyrock induced by blasting. Eng Comput 2019:1-14. https://doi.org/10.1007/s00366-019-00816-y.

[5] Zhou J, Aghili N, Ghaleini EN, Bui DT, Tahir MM, Koopialipoor M. A Monte Carlo simulation approach for effective assessment of flyrock based on intelligent system of neural network. Eng Comput 2020;36(2):713-23.

[6] Koopialipoor M, Ghaleini EN, Haghighi M, Kanagarajan S, Maarefvand P, Mohamad ET. Overbreak prediction and optimization in tunnel using neural network and bee colony techniques. Eng Comput 2019;35(4):1191-202.

[7] Xu Z, Zou B, Wang J, Luo Z, Liu X, Hu L, et al. Evaluation of impact level of blasting-induced over-break by probabilistic neural network. Arab J Geosci 2020;13(16):1-13.
[8] Nanda SK, Tripathy DP, Patra SK. Development of an artificial neural network based noise prediction model for opencast mines. Noise Control Eng J 2010;58(2):105-20.

[9] Nanda SK, Tripathy DP. Application of functional link artificial neural network for prediction of machinery noise in opencast mines. Adv Fuzzy Syst 2011:1-11. Article ID 831261.

[10] Utley WA. Noise from opencast coal mining sites. Appl Acoust 1980;13(2):85-102.

[11] Pathak K, Durucan S, Kunimatsu S. Activity accounting technique for environmental noise assessment in mechanized surface mining. Environ Monit Assess 1999;56(3): 241-56.

[12] Bansah KJ, Assan E, Bosompem C. Predicting the levels of noise from quarry operations. In: 24th International Mining Congress and Exhibition of Turkey-IMCET'15 Antalya, Turkey, April 14-17, 2015; 2015. p. 1492-6.

[13] Manwar VD, Mandal BB, Pal AK. Environmental propagation of noise in mines and nearby villages: a study through noise mapping. Noise \& Health 2016;18(83):185-93.

[14] Nanda SK, Tripathy DP, Patra SK. Fuzzy inference systembased noise prediction models for opencast mines. Int J Min Reclamat Environ 2009;23(4):242-60.

[15] Rabeiy RE, Mohamed M, Gomma W. Study on the noise prediction in mining and industrial plants. Assiut University Bull Environ Res 2004;7(2):77-89.

[16] Lokhande SK, Dhawale SA, Pathak SS, Gautam R, Jain MC, Bodhe GL. Appraisal of noise level dissemination surrounding mining and industrial areas of Keonjhar, Odisha: a comprehensive approach using noise mapping. Arch Acoust 2017;42(3):423-32.

[17] Zhang X, Zhao M, Dong R. Time-series prediction of environmental noise for urban IoT based on long short-term memory recurrent neural network. Appl Sci 2020;10(3):1144 https://doi.org/10.3390/app10031144. 2020.

[18] Genaro N, Torija A, Ramos-Ridao A, Requena I, Ruiz DP, Zamorano M. A neural network based model for urban noise prediction. J Acoust Soc Am 2010;128(4):1738-46.

[19] Cao J, Cao M, Wang J, Yin C, Wang D, Vidal PP. Urban noise recognition with convolutional neural network. Multimed Tool Appl 2019;78(20):29021-41.

[20] Ruscher CJ, Gogineni S, Tenney AS, Glauser MN. Jet noise prediction via low-order machine learning. In AIAA Scitech 2019 Forum (p. 0547).

[21] Brown CA, Dowdall J, Whiteaker B, McIntyre L. A machine learning approach to Jet-surface interaction noise modeling. In: AIAA SciTech Forum, 6-10 January 2020; 2020. p. 1-16.

[22] Yang Y, Hinde C, Gillingwater D. Airport noise simulation using neural networks. In: 2008 IEEE International Joint Conference on Neural Networks (IEEE World Congress on Computational Intelligence): 1917-1923; 2008.

[23] Cenedese F, Clerici A. Helicopter noise prediction using artificial neural network tool as an alternative to multiple regression. In: Inter-Noise and Noise-Con Congress and Conference Proceedings; 2007. p. 1358-68 (6).

[24] Nedic V, Despotovic D, Cvetanovic S, Despotovic M, Babic S. Comparison of classical statistical methods and artificial neural network in traffic noise prediction. Environ Impact Assess Rev 2014;49:24-30.

[25] Sharma M, Dahiya M, Saini PK, Garg N. Application of artificial neural network for modelling of traffic noise on roads in Delhi. IOSR J Mech Civ Eng 2012;1:31-6.

[26] Nayef MA, Rukaibi AF. Neural network models for traffic noise quality prediction: a comparative study. J Civ Environ Eng 2012;2(1):1-5. 2012.

[27] Doolan BL. The use of artificial intelligence to predict road traffic noise. Doctoral dissertation. University of Tasmania; 2008.

[28] Lotfi E, Akbarzadeh-T MR. A winner-take-all approach to emotional neural networks with universal approximation property. Inf Sci 2016;346:369-88.

[29] Pavlos GP, Iliopoulos AC, Tsoutsouras VG, Sarafopoulos DV, Sfiris DS, Karakatsanis LP, et al. First and second order nonequilibrium phase transition and evidence for non-extensive 
Tsallis statistics in Earth's magnetosphere. Physica A 2011; 390(15):2819-39.

[30] Babaie T, Karimizandi R, Lucas C. Learning based brain emotional intelligence as a new aspect for development of an alarm system. Soft Comput 2008;12(9):857-73.

[31] Lotfi E, Khosravi A, Akbarzadeh-T MR, Nahavandi S. Wind power forecasting using emotional neural networks. Proceedings of the 2014 IEEE International Conference on Systems, Man, and Cybernetics, vol. 2014. SMC; 2014. p. 311-6. 2014.

[32] Sharghi E, Nourani V, Najafi H, Gokcekus H. Conjunction of a newly proposed emotional ANN (EANN) and wavelet transform for suspended sediment load modeling. Water Supply 2019;19(6):1726-34. 2019.

[33] Nourani V. An Emotional ANN (EANN) approach to modeling rainfall-runoff process. J Hydrol 2017;544:267-77.

[34] Sharghi E, Nourani V, Molajou A, Najafi H. Conjunction of emotional ANN (EANN) and wavelet transform for rainfallrunoff modeling. J Hydroinf 2018;21(1):136-52.

[35] Sharghi E, Nourani V, Najafi H, Molajou A. Emotional ANN (EANN) and wavelet-ANN (WANN) approaches for Markovian and Seasonal based modeling of rainfall-runoff process. Sustain Water Resour Manag 2018;32(10):3441-56. 2018.

[36] Nourani V, Molajou A, Üzelaltõnbulat S, Sadikoglu F. Emotional artificial neural networks (EANNs) for multi-step ahead prediction of monthly precipitation; case study: northern Cyprus. Theor Appl Climatol 2019;138:1419-34.

[37] Wang X, Peng Q, Fan Y. Detecting susceptibility to breast cancer with SNP-SNP interaction using BPSOHS and emotional neural networks. BioMed Res Int 2016;5164347:1-7.

[38] Balkenius C, Morén J. Emotional learning: a computational model of amygdala. Cybern Syst 2001;32(6):611-36.

[39] Scherer KR, Bänziger T, Roesch E. A blueprint for affective computing: a sourcebook and manual. 1st ed. Oxford University Press; 2010.

[40] Nourani V, Molajou A, Üzelaltõnbulat S, Sadikoglu F. Emotional artificial neural networks (EANNs) for multi-step ahead prediction of monthly precipitation; case study: northern Cyprus. Theor Appl Climatol 2019;138:1419-34.

[41] Obosu JK, Kuma JSY, Buah WK. Estimation of the quantity of water in the abandoned underground mine of gold fields Ghana limited Tarkwa: a potential source to augment water supply to Tarkwa municipality". Ghana Mining J 2019;19(1): 9-11.

[42] Amiri M, Bakhshandeh AH, Hasanipanah M, Mohammad KL. A new combination of artificial neural network and K-nearest neighbors models to predict blastinduced ground vibration and air-overpressure. Eng Comput 2016;32(4):631-44.

[43] Swingler K. Applying neural networks: a practical guide. New York: Academic Press; 1996.

[44] Taheri K, Hasanipanah M, Golzar SB, Majid MZA. A hybrid artificial bee colony algorithm-artificial neural network for forecasting the blast-produced ground vibration. Eng Comput 2017;33(3):689-700.

[45] Sayevand K, Arab H. A fresh view on particle swarm optimization to develop a precise model for predicting rock fragmentation. Eng Comput 2019;36(2):533-50.

[46] Tiile RN. Artificial neural Network approach to predict blastinduced ground vibration, airblast and rock fragmentation. Master's Dissertation. Rolla: Missouri University of Science and Technology; 2016.

[47] Mohamad ET, Armaghani DJ, Hasanipanah M, Murlidhar BR, Alel MNA. Estimation of air-overpressure produced by blasting operation through a neuro-genetic technique. Environ Earth Sci 2016;75(2):1-15.

[48] Nguyen H, Bui XN, Bui HB, Mai NL. A comparative study of artificial neural networks in predicting blast-induced airblast overpressure at Deo Nai open-pit coal mine, Vietnam. Neural Comput Appl 2020;32(8):3939-55.

[49] Nguyen H, Bui XN. Predicting blast-induced air overpressure: a robust artificial intelligence system based on artificial neural networks and random forest. Nat Resour Res 2019;28(3):893-907.

[50] Mohamad ET, Hajihassani M, Armaghani DJ, Marto A. Simulation of blasting-induced air overpressure by means of artificial neural networks. Int RevModelling and Sim 2012; 5(6):2501-6.

[51] AminShokravi A, Eskandar H, Derakhsh AM, Rad HN, Ghanadi A. The potential application of particle swarm optimization algorithm for forecasting the air-overpressure induced by mine blasting. Eng Comput 2018;34(2):277-85.

[52] Hasanipanah M, Shahnazar A, Bakhshandeh Amnieh $H$, Armaghani DJ. Prediction of air-overpressure caused by mine blasting using a new hybrid PSO-SVR model. Eng Comput 2017;33(1):23-31.

[53] Gao W, Alqahtani AS, Mubarakali A, Mavaluru D, khalafi S. Developing an innovative soft computing scheme for prediction of air overpressure resulting from mine blasting using GMDH optimized by GA. Eng Comput 2020;36(2): 647-54.

[54] Armaghani DJ, Hasanipanah M, Mahdiyar A, Majid MZA, Bakhshandeh Amnieh $\mathrm{H}$, Tahir MMD. Airblast prediction through a hybrid genetic algorithm-ANN model. Neural Comput Appl 2018;29(9):619-29.

[55] Muller AV, Hemond HF. Extended artificial neural networks: incorporation of a priori chemical knowledge enables use of ion selective electrodes for in-situ measurement of ions at environmentally relevant levels. Talanta 2013;117:112-8.

[56] Adeoti OA, Osanaiye PA. Effect of training algorithms on the performance of ANN for pattern recognition of bivariate process. Int J Comput Appl 2013;69(20):8-12.

[57] Mathias AC, Rech PC. Hopfield neural network: the hyperbolic tangent and the piecewise-linear activation functions. Neural Network 2012;34:42-5. 